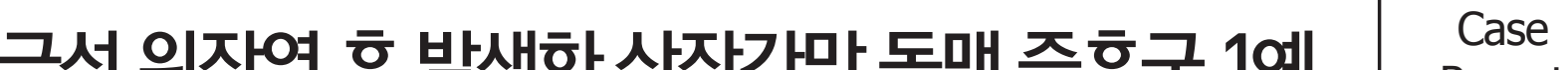 급성 위장염 후 달생한 상장간막 동맥 증후군 1예| Report
}

이승범, 강희철 ${ }^{1 *}$, 윤유정 ${ }^{1}$

동신병원, ${ }^{1}$ 연세대학교 의과대학 가정의학교실

\section{A Case Report of Superior Mesenteric Artery Syndrome after Acute Gastroenteritis}

\author{
Seung-Beom Lee, Hee-Cheol Kang ${ }^{1, *}$, Yu-Jung Yoon ${ }^{1}$ \\ Dongshin General Hospital, ${ }^{1}$ Department of Family Medicine, Yonsei University College of Medicine, Seoul, Korea
}

The most common cause of small bowel obstruction is postoperative adhesion, and besides a hernia, metastatic or primary cancer and small bowel tumors are possible causes. Superior mesenteric artery (SMA) syndrome is a rare cause of upper gastrointestinal obstruction and is associated with debilitating conditions with marked weight loss. SMA syndrome results from the compression of the third part of the duodenum due to the narrowing of the aortomesenteric angle. We report a 28-year-old woman with SMA syndrome after acute gastroenteritis. Her stomach was severely dilated due to the duodenal obstruction and computed tomography showed the compression of the third portion of the duodenum by SMA. She was conservatively cared for and thus favorably improved.

Keywords: Superior Mesenteric Artery Syndrome; Small Bowel Obstruction; Weight Loss

서론

소장 폐색의 가장 흔한 원인은 수술 후 유착이 $70 \%$ 이상으 로 가장 많고, 탈장이 $20 \%$ 정도이며 그 밖에도 대장암, 소장 종 양, 크론병, 소장 염전 등이 있다. ${ }^{1)}$ 드문 원인으로는 상장간막 동맥에 의해서 십이지장이 압박을 받음으로써 발생하는 상장 간막 동맥 증후군(superior mesenteric artery syndrome)이 있다. ${ }^{2)}$ 이 질환은 1861년 Von Rokitansky가 처음 기술하였고 1921년에 Wilkie가 64예를 분석하여 보고한 이래로 Wilkie 증후군, 석고 붕대 증후군, 만성 십이지장 폐색, 만성 십이지장 정체, 십이지 장의 혈관 압박 등 다양한 명칭으로 불려왔다. ${ }^{3}$ 해부학적으로

Received: July 20, 2009, Accepted: October 26, 2010

${ }^{*}$ Corresponding Author: Hee-Cheol Kang

Tel: 02-2228-2330, Fax: 02-362-2473

E-mail: kanghc@yuhs.ac

Korean Journal of Family Medicine

Copyright $@ 2010$ by The Korean Academy of Family Medicine
복부 대동맥과 상장간막 동맥 사이에는 장간막 지방층이 있 어서 각도가 유지되는데, 어떤 원인으로 인하여 지방조직이 감소하면 두 동맥 사이의 각이 줄어들고 간격이 좁아지면 십 이지장의 제 3 부위에 해당하는 횡행부가 압박을 받는다.

상장간막 동맥 증후군을 유발하는 요인들은 화상, 악성종 양, 외상에 의한 석고 붕대, 척추 질환으로 수술, 섭식장애 또는 흡수장애 등이 알려져 있다. ${ }^{4)}$ 이에 저자들은 평소에 마른 체형 이던 28세 여자가 심한 급성 위장염을 않고 난 후에 복통과 오 심이 지속되었고, 복부 전산화단층촬영 검사에서 소장 폐쇄 의 원인을 상장간막 동맥 증후군으로 확인한 증례를 경험하 여 문헌 고찰과함께 보고하는 바이다.

\section{증례}

28세 여자 환자가 내원 3일 전부터 발생한 오심과 소화불 량을 주소로 내원하였다. 환자는 내원 2주 전 고열과 수양성 설사로 인하여 $3 \mathrm{~kg}$ 의 체중 감소가 있었다고 하며, 그 이후로 식후에 소화가 잘 안되고 복부 팽만감이 있어서 특별한 치료 
를 하지 않고 지냈다고 한다. 내원 1 일 전부터는 복부 통증이 심하고, 상복부의 팽만이 있어서 본원의 응급실을 경유하여 입원하였다. 과거력상 23 세경 폐결핵을 않았으며 그 외에는 특이 병력이나가족력은 없었다.

내원 당시 생체 징후는 혈압 $110 / 70 \mathrm{mmHg}$, 맥박수 80/ minute, 호흡수 $20 /$ minute, 체온 $37.3^{\circ} \mathrm{C}$ 이었다. 신장은 $161 \mathrm{~cm}$, 체중 $40 \mathrm{~kg}$ 으로 체질량지수(body mass index, BMI)는 $15.4 \mathrm{~kg}$ / $\mathrm{m}^{2}$ 로 심한 저체중 상태였다. 외관상 급성 병색을 보였으며 앙 상하게 마른 체격으로 피부는 거칠고 탄력이 감소해 있었다. 혀와 입술은 말라 보였고, 겨드랑이에서는 땀이 없었다. 복부 진찰에서는 장음이 감소하였으며, 약간 경직되어 있었고 팽 창되었다. 타진상 고음(tympanic sound)이 있었으며, 압통은 약하게복부 전체에 있었다.

검사실 소견으로 일반혈액검사에서 백혈구 $6,000 / \mathrm{mm}^{3}$,
다핵구는 $91.5 \%$ 로 증가되었고, 혈색소 $10.8 \mathrm{~g} / \mathrm{dL}$, 혈소판 $301,000 / \mathrm{mm}^{3}$ 이었다. 생화학 검사에서 총단백 $7.5 \mathrm{~g} / \mathrm{dL}$, 알부민 $5.0 \mathrm{~g} / \mathrm{dL}$, 총빌리루빈 $0.4 \mathrm{mg} / \mathrm{dL}$, aspartate aminotransferase $32 \mathrm{U} /$ $\mathrm{L}$, alanine aminotranferease $15 \mathrm{U} / \mathrm{L}$, blood urea nitrogen $6 \mathrm{mg} / \mathrm{dL}$, creatinine $0.8 \mathrm{mg} / \mathrm{dL}, \mathrm{Na} 142 \mathrm{mEq} / \mathrm{L}, \mathrm{K} 4.2 \mathrm{mEq} / \mathrm{L}$, amylase 145 $\mathrm{U} / \mathrm{L}$, lipase $18 \mathrm{U} / \mathrm{L}$ 이었다. 소변검사와 갑상선기능 검사는 정 상이었다.

복부단순촬영에서 십이지장으로 보이는 소장의 팽창이 있었고, 좌상복부에서 음식물로 보이는 커다란 음영이 관찰 되었다(Figure 1). 소장 폐쇄를 의심하여 응급으로 시행한 복 부조영 computed tomography (CT)검사에서는 위장의 심한 팽 창과 과도한 양의 음식물이 채우고 있음을 확인하였다. 그리 고 십이지장의 구부와 하행부(제 2 부위)가 팽창해 있었으며 횡행부(제 3 부위)는 상장간막 동맥과 복부 대동맥 사이에서
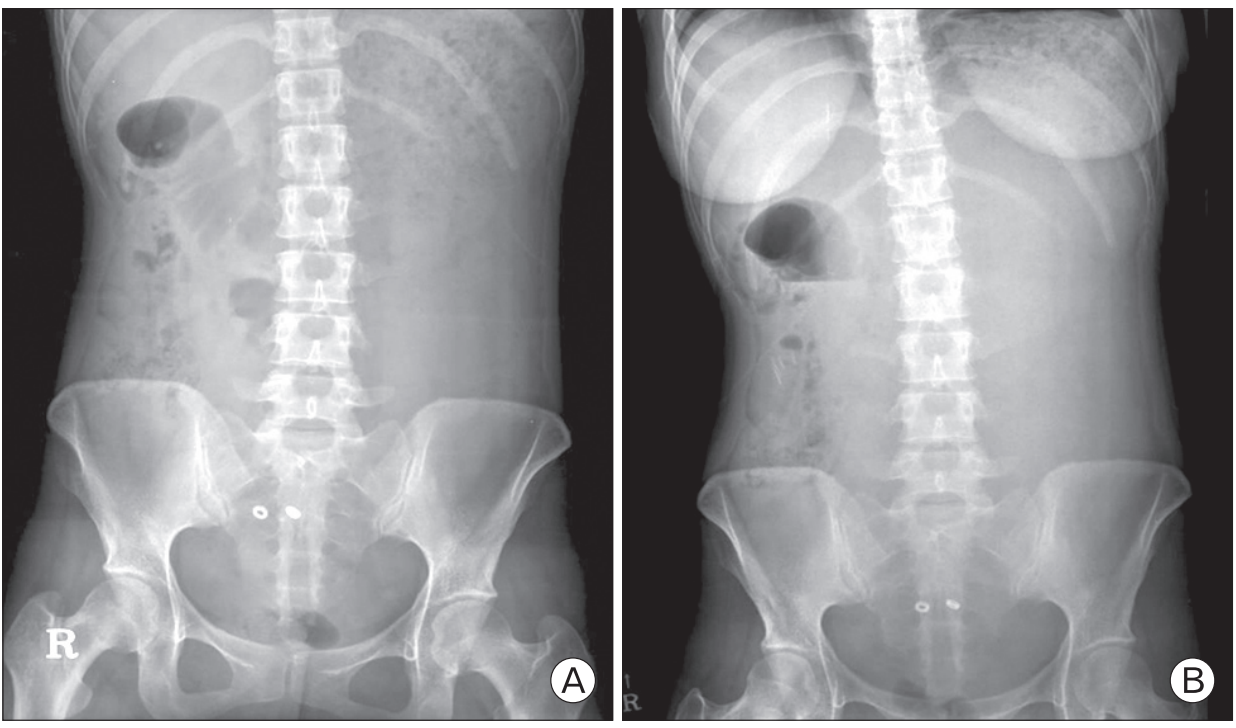

Figure 1. (A) Plain abdominal $\mathrm{X}$-ray supine position. (B) Plain abdominal X-ray errect position. Both pictures showed the dilated small bowel at the right upper quadrant and large food material of the stomach.
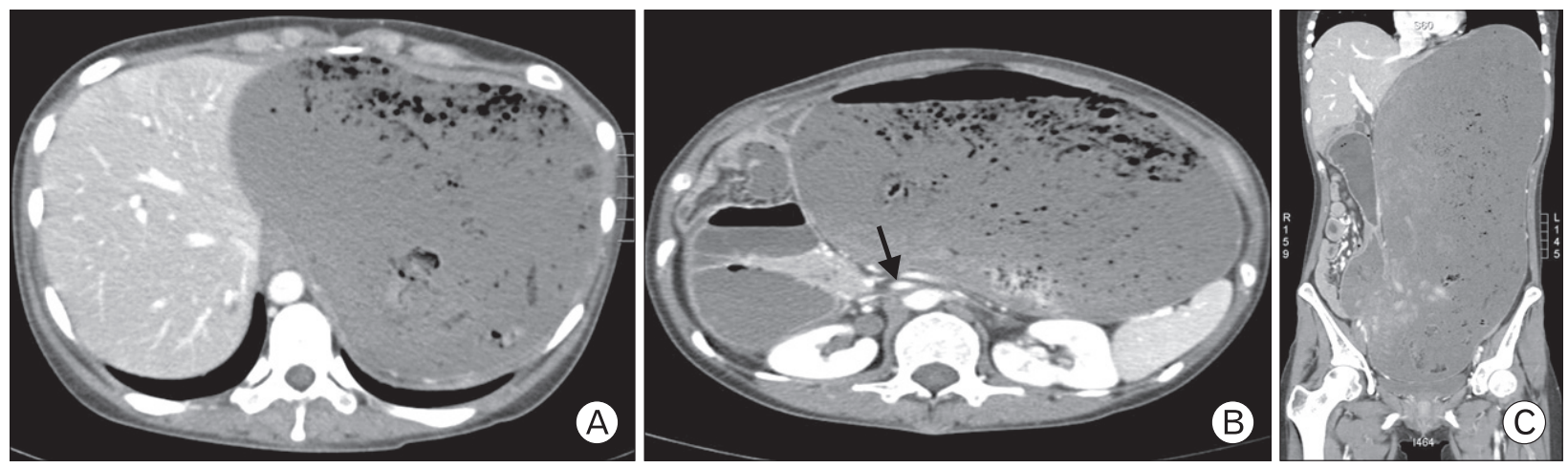

Figure 2. (A) Contrast computed tomography showed severe dilatation and food retention of the stomach. (B) It showed dilated bulb and 2nd portion of the duodenum. The distance between the superior mesenteric artery and abdominal aorta was $4 \mathrm{~mm}$ (arrow). (C) The dilated stomach was extended to pelvic cavity and the gas amount of colon was little. 
압박된 소견을 보였다. 상장간막 동맥과 복부 대동맥 사이의 거리는 $4 \mathrm{~mm}$ 로 좁아져 있었다(Figure 2).

저자들은 환자의 급격한 체중감소를 동반한 저체중과 복 부 CT검사의 결과를 고려하여 소장 폐쇄의 원인을 상장간막 동맥 증후군으로 진단하였다. 일반외과에서 협의진료를 하 였으며 환자의 나이가 젊고 다른 동반 질환이 없으므로 수술 보다는 보존적 치료를 먼저 시행하기로 결정하였다. 비위관 (naso-gastric tube)을 삽입하여 위장을 감압하였고, 전비경구적 영양공급을 시작하였다. 환자는 슬흥위(knee-chest position), 좌측 측와위 또는 복와위로 자세를 변경하면서 십이지장의 횡행부가압박되지 않도록하였다.

입원 2일에 복통과 오심 증세가 감소하였고, 복부영상검 사에서 대장의 가스 음영이 관찰되었다(Figure $3 \mathrm{~A}$ ). 환자의 상 태가 안정적이고, 임상적 호전이 있어서 수술적 치료보다는 보존적 치료를 지속하며 경과를 관찰하기로 결정하였다. 입 원 3일에 환자는 방귀와 대변이 나오고 복부 불편감이 감소했 으며, 코와 인후의 불편을 심하게 호소하여 비위관을 제거하 였다. 추적 복부영상검사에서 소장의 팽창이 감소하고 위장 음영의 크기가 상당히 줄어 있었다(Figure 3B). 입원 4일부터 는 복부에 불편함은 호소하지 않았으나, 설사가 하루 4-5회 정도 있었다. 입원 5 일부터 연식으로 경구 영양 섭취를 시작하 였고, 입원 6일에 퇴원하여 현재 외래 추적관찰 중이다.
고찰

상장간막 동맥 증후군은 흔하지 않지만 간과될 수 있는 질 환인데, 유발하는 요인들은 크게 다섯 가지 범주로 나뉠 수 있 다: 1) 암이나 화상 같은 심한 소모성 질환들; 2) 두부 외상 같 은 심한 외상; 3) 척추 질환, 척추 기형 또는 석고부목을 포함하 는 외상; 4) 거식증 또는 흡수장애 등의 원인으로 인한 영양장 애; 5) 척추 측만증의 교정을 위한 수술이나 기타 수술을 받은 경우 등이다. ${ }^{3,5)}$ 그 밖에도 보고된 증례에 따르면 복부 대동맥 류(aortic aneurysm), 폐암 또는 대장암의 복막 전이, 당뇨성 케 톤산증 등의 질환에 의해서 소장 폐쇄가 나타날수 있다. ${ }^{6-10)}$

진단의 과정은 일반적으로 소장 폐쇄의 다른 원인들을 배 제하는 것이 우선이다. 젊은 환자에서 마른 체격에 연약해 보 이고, 최근 심한 체중 감소가 있었거나 식사와 관련한 복부 불 편감이 동반되면 의심해본다. 감별할 질환에는 장유착, 소화 성 궤양, 담도질환, 췌장염 또는 췌장 낭종, 복강내 악성 종양, Crohn 병, 신경성 식욕부진증, 신경성 대식증 등이 있다.

본 증례의 환자는 내원 2주 전에 고열과 수양성 설사 증세 가 있었던 병력으로 미루어 보아 급성 위장염으로 인한 체중 감소가 유발 원인으로 추정되었다. 상장간막 동맥 증후군은 발생 기전이 감염성 질환이 아니므로 고열을 유발하기 어렵 다. 감별할 질환으로 신경성 식욕부진증이 있는데, 환자는 마 른 체격이지만 자신의 질병 상태를 이해하고 있었고 음식물
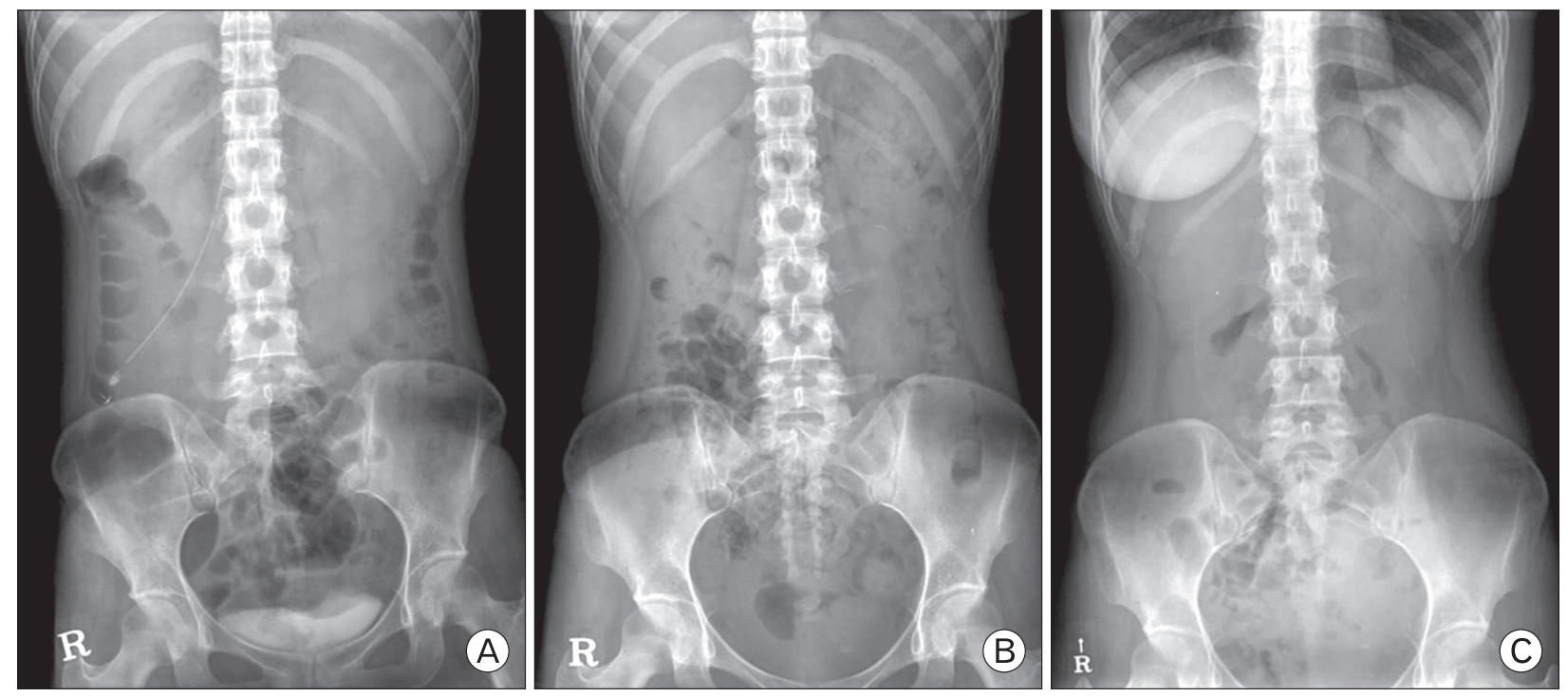

Figure 3. (A) Follow-up supine abdominal X-ray on the 2nd day of admission showed the passage of gas to the colon. (B) Plain X-ray of the 3rd day of admission showed the decreased stomach size and the decreased gas amount of the small intestine. (C) It showed that the small bowel ileus was improved on the 6th day of admission. 
섭취에 공포나 거부감을 드러내지 않아서 DSM-IV 진단기준 에 합당하지 않았다. 저자들은 관련된 문헌을 검색하여 검토 를 하였고, 마른 체격과 심한 체중 감소가 유발요인이라는 여 러 보고는 볼 수 있었지만 급성 위장염으로 인하여 발생한 증 례는 찾아보기 힘들었다.

모든 환자에서 전형적으로 소장 폐쇄의 증상과 징후가 나 타나는데, 즉 오심, 구토, 식후 복통, 복부 팽만감, 고음, 압통 그 리고 비정상적인 장음 등이 있으며 이런 증상들이 급성으로 나타날 수도 있고 만성적으로 나타나기도 한다.,11) 구토를 하 면 내용물에는 담즙이 포함되어 있고, 구토를 한 이후에는 증 상이 완화된다. 위장에서 음식물의 배출을 촉진하여 환자의 증상을 개선시키는 좌측 측와위나 복와위 또는 슬흥위 자세 도 진단에 도움을 주는 단서가 된다. 복통이나 오심과 구토가 질환에 의해서 나타나는 증상이지만, 환자로 하여금 음식물 섭취를 꺼리게 만들고 체중을 더욱 감소시켜서 증상을 악화 시키는 요인으로도 작용한다. 게다가 이런 증상들의 심한 정 도나 발현이 다양하고, 특히 증상이 없는 기간에는 오진을 하 게 만들 수도 있다. ${ }^{12}$

진단을 위한 검사에는 상부위장관 촬영, 복부 초음파, 전 산화 단층촬영, 혈관조영술, magenetic resornance angiography (MRA) 등을 이용한다. 바륨 상부위장관 촬영에서는 위장과 십이지장의 제 1,2 부위가 확장되고 제 3 부위(횡행부)에서 횡 단된 외부 압박 소견과 바륨의 지연성 통과를 관찰할 수 있다. ${ }^{13)}$ 복부 초음파 검사로 색채 도플러를 이용하여 aorto-mesenteric angle을 측정하면, 정상 범위는 $25-60^{\circ}$ 지만 상장간막 동맥 증 후군에서는 $25^{\circ}$ 미만의 좁은 각을 보인다. ${ }^{12)}$ 복부 전산화 단층 촬영은 초음파 검사보다 확실하게 aorto-mesenteric distance를 측정할 수 있는데, 정상적으로 10-28 mm이지만 상장간막 동 맥 증후군에서는 2-8 mm로 감소해 있다., ${ }^{2,14)}$ Aorto-mesenteric angle은 고식적 혈관조영술 뿐만 아니라 CT angiography, MRA 를 사용하여 3 차원적으로 측정할 수 있다. ${ }^{15,16)}$ 상부위장관 내 시경은 다른 질환을 배제하기 위해서 시행하며 음식물 저류 와 위식도 역류, 십이지장의 팽대와 retroperistalsis를 관찰할 수 있다. ${ }^{11,17)}$ 소장내시경(enteroscopy)을 사용하면 십이지장의 제3부위에서 박동성 외부 압박을 볼 수 있고, 초음파 내시경 (endoscopic ultrasonography, EUS)으로 aorto-mesenteric distance 의 측정이 가능하다. ${ }^{18)}$

치료는 초기에 비수술적인 내과적 방법을 시도하고, 양 성 질소균형 상태(positive nitrogen balance)를 만들어서 후복막 지방층을 회복시켜야 한다. 식사가 어려운 경우에는 비공장 (nasojejunal) 튜브를 이용한 영양 공급을 하거나, 전비경구적 영양 공급을 사용한다. 식사가 가능하다면 식후에 소장 폐쇄
를 완화시켜주는 좌측위, 슬흥위 자세를 유지시켜 위장의 음 식물 배출을 촉진한다. ${ }^{3)}$ Merrett 등 ${ }^{13)}$ 은 소아나 증례의 환자처 럼 병력이 짧은 성인에서 보존적 치료가 효과를 보일 수 있지 만, 만성적인 성인 환자에서는 종종 낮은 성공률과 장기간 입 원을 요한다고 보고하였다.

수술 적응증은 보존적인 방법으로 호전되지 않거나, 소 장 폐쇄를 완화시켜주는 자세를 적절히 수행할 수 없는 경우, 천공이나 출혈이 있는 경우 등이 해당한다. ${ }^{19)}$ 수술방법은 세 가지 술기가 있으며, 위공장문합술, 십이지장공장문합술 및 Treitz 인대로부터 십이지장을 박리하는 Strong 술식이 이용된 다. ${ }^{13)}$ 이 중에서 십이지장공장문합술이 가장 많이 사용되고 최근에는 복강경을 이용한 수술이 가능하다. ${ }^{19-21)}$

결론은 마른 체격이거나 심한 체중 감소가 있으면서 급성 또는 만성적인 상부 위장관 폐색이 있고, 특별한 원인을 찾지 못한 경우에는 상장간막 동맥 증후군을 의심할 필요가 있으 며 적절한 영상학적 검사를 실시하면 드문 질환이지만 간과 하지 않고 조기에 치료할수 있다.

요약

상장간막 동맥 증후군(superior mesenteric artery syndrome) 은 상장간막 동맥에 의해서 십이지장이 압박을 받음으로써 소장 폐쇄가 일어나는 질환이다. 해부학적으로 복부 대동맥 과 상장간막 동맥 사이에는 장간막 지방층이 있어서 각도가 유지되는데, 어떤 원인으로 인하여 지방조직이 감소하면 두 동맥 사이의 각이 줄어들고 간격이 좁아지면 십이지장의 제3 부위에 해당하는 횡행부가 압박을 받아 소장 폐쇄가 발생하 는 병으로 원인은 화상, 악성종양, 외상에 의한 석고 붕대, 척추 질환으로 수술, 섭식장애 또는 흡수장애 등이 알려져 있다. 드 물게 28세 여자환자가 급성위장염으로 인한 체중감소로 상장 간막 동맥 증후군이 발생하여 입원하여 보존치료 후 회복하 였기에 이를 증례보고 한다.

중심단어: 상장간막 동맥 증후군; 소장 폐쇄; 체중감소

\section{REFERENCES}

1. Markogiannakis H, Messaris E, Dardamanis D, Pararas N, Tzertzemelis D, Giannopoulos P, et al. Acute mechanical bowel obstruction: clinical presentation, etiology, management and 
outcome. World J Gastroenterol 2007;13:432-7.

2. Gustafsson L, Falk A, Lukes PJ, Gamklou R. Diagnosis and treatment of superior mesenteric artery syndrome. Br J Surg 1984;71:499-501.

3. Hines JR, Gore RM, Ballantyne GH. Superior mesenteric artery syndrome. Diagnostic criteria and therapeutic approaches. Am J Surg 1984;148:630-2.

4. Noorani A, Walsh SR, Cooper DG, Varty K. Entrapment syndromes. Eur J Vasc Endovasc Surg 2009;37:213-20.

5. Crowther MA, Webb PJ, Eyre-Brook IA. Superior mesenteric artery syndrome following surgery for scoliosis. Spine (Phila Pa 1976) 2002;27:E528-33.

6. Saraya T, Kurai D, Ariga M, Nakamoto K, Koide T, Tamura $\mathrm{M}$, et al. Superior mesenteric artery syndrome caused by huge mycotic abdominal aortic aneurysm. Intern Med 2009;48:10658.

7. Kim HR, Park MW, Lee SS, Shin MJ, Park JH, Yang CW, et al. Superior mesenteric artery syndrome due to an aortic aneurysm in a renal transplant recipient. J Korean Med Sci 2002;17:552-4.

8. Bang CS, Lee SI, Park GW, Kang HY, La SS, Kong JH, et al. A case of superior mesenteric artery syndrome due to peritoneal seeding in a colon cancer patient. Korean J Med 2009;76:380-4.

9. Ryu BY, Cho JW, Kim HK, Suk H, Namkung S. Superior mesenteric artery syndrome: report of three cases. J Korean Surg Soc 1999;57:764-70.

10. Han MS, Koh KW, Kim YM, Kang MS, Choe DH, Kim HR, et al. Two different causes of intestinal obstruction in lung cancer. Tuberc Respir Dis 2009;66:365-9.

11. Chun JS, Chung WC, Hwang SS, Cho HM, Lee KM, Lee $\mathrm{BI}$, et al. A case of superior mesenteric artery syndrome treated by laparoscopic surgery. Korean J Gastrointest Endosc 2006;32:215-20.
12. Neri S, Signorelli SS, Mondati E, Pulvirenti D, Campanile E, Di Pino L, et al. Ultrasound imaging in diagnosis of superior mesenteric artery syndrome. J Intern Med 2005;257:346-51.

13. Merrett ND, Wilson RB, Cosman P, Biankin AV. Superior mesenteric artery syndrome: diagnosis and treatment strategies. J Gastrointest Surg 2009;13:287-92.

14. Ozkurt H, Cenker MM, Bas N, Erturk SM, Basak M. Measurement of the distance and angle between the aorta and superior mesenteric artery: normal values in different BMI categories. Surg Radiol Anat 2007;29:595-9.

15. Konen E, Amitai M, Apter S, Garniek A, Gayer G, Nass S, et al. $\mathrm{CT}$ angiography of superior mesenteric artery syndrome. AJR Am J Roentgenol 1998;171:1279-81.

16. Gerasimidis T, George F. Superior mesenteric artery syndrome. Wilkie syndrome. Dig Surg 2009;26:213-4.

17. Moon SW, Park H, Mun JS, Myoung BH, Kim DH, Kim HD, et al. A case of superior mesenteric artery syndrome with hematemesis. Korean J Med 2009;76:727-31.

18. Lippl F, Hannig C, Weiss W, Allescher HD, Classen M, Kurjak M. Superior mesenteric artery syndrome: diagnosis and treatment from the gastroenterologist's view. J Gastroenterol 2002;37:6403.

19. Makam R, Chamany T, Potluri VK, Varadaraju PJ, Murthy $\mathrm{R}$. Laparoscopic management of superior mesentric artery syndrome: a case report and review of literature. J Minim Access Surg 2008;4:80-2.

20. Morris TC, Devitt PG, Thompson SK. Laparoscopic duodenojejunostomy for superior mesenteric artery syndrome-how I do it. J Gastrointest Surg 2009;13:1870-3.

21. Bermas H, Fenoglio ME. Laparoscopic management of superior mesenteric artery syndrome. JSLS 2003;7:151-3. 